\title{
The influence of methods of bariatric surgery for treatment of type 2 diabetes mellitus
}

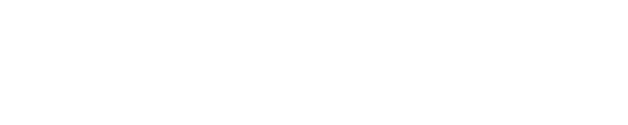

\author{
Marek Bužga' \\ Petra Maresova ${ }^{2}$ \\ Adela Seidlerova' \\ Pavel Zonča' \\ Pavol Holéczy' \\ Kamil Kuča ${ }^{2,3}$ \\ 'Research Obesity Center, Faculty \\ of Medicine, University of Ostrava, \\ Ostrava, Czech Republic; ${ }^{2}$ Faculty \\ of Informatics and Management, \\ University of Hradec Kralove, Hradec \\ Kralove, Czech Republic; ${ }^{3}$ Biomedical \\ Research Center, University Hospital \\ Hradec Kralove, Hradec Kralove, \\ Czech Republic
}

\begin{abstract}
The constantly growing incidence of obesity represents a risk of health complications for individuals, and is a growing economic burden for health care systems and society. The aim of this study was to evaluate the efficacy of bariatric surgery, specifically laparoscopic greater curve plication, laparoscopic sleeve gastrectomy, and Roux-en-Y gastric bypass, in patients with type 2 diabetes mellitus. The effect of bariatric surgery on the changes in blood pressure before, and 12 months after, surgery and in pharmacotherapy in the 12 months after surgery was analyzed. For achieving this purpose, 74 patients from the Obesity and Surgery Department of Vitkovice Hospital in Ostrava in the Czech Republic, were monitored. They were operated in 2011 and 2012. The Bonferroni method was used to test hypotheses about the impact of surgery on blood pressure and pharmacotherapy. One year after the surgery, systolic and diastolic blood pressure values decreased, both with no statistically significant difference between surgery types. Improvement was observed in $68 \%$ of cases, with $25 \%$ of patients discontinuing pharmacotherapy entirely.
\end{abstract}

Keywords: type 2 diabetes mellitus, bariatric surgery, blood pressure, pharmacotherapy

\section{Introduction}

There are more than 2.1 billion obese people worldwide, amounting to approximately $30 \%$ of the world population. Further increases are expected in the future, with an estimated $50 \%$ of the population becoming obese by 2030 . Body weight is generally assessed with the body mass index (BMI). Excess body weight is defined as a BMI between 25.0 and $29.9 \mathrm{~kg} / \mathrm{m}^{2}$. A BMI of 30 or higher is considered obesity. Obesity affects 2.5 times as many people as malnutrition. Obesity is responsible for $5 \%$ of all deaths, and its economic impact corresponds to $2.8 \%$ of the gross domestic product, making its effects comparable to those of smoking, war, and terrorism. ${ }^{1}$ Obesity not only increases the risk of health complications for the individual but increasing obesity rates also represent a significant and steadily growing burden for health care systems and society as a whole.

Maglione et $\mathrm{al}^{2}$ investigated the outcomes of four surgical procedures in patients with a BMI over $30 \mathrm{~kg} / \mathrm{m}^{2}$ : laparoscopic adjustable gastric banding (LAGB), Roux-en-Y gastric bypass (RYGB), biliopancreatic diversion with duodenal switch, and laparoscopic sleeve gastrectomy (LSG). These studies confirmed the high efficacy of these methods compared to conventional methods and the greater efficacy of RYGB and LAGB in providing significant, relatively permanent weight loss. Fried et $\mathrm{al}^{3}$ also confirmed the effect of surgical procedures on obesity. Surgery resulted in long-term success (ie, lasting 5 years or longer) in over $80 \%$ of patients, whereas conservative treatment failed in approximately $80 \%$ of patients. It has also been shown that metabolic surgery significantly decreases mortality among obese patients and also decreases the
Correspondence: Kamil Kuča Faculty of Informatics and Management, University of Hradec Kralove, Rokitanského 62, 50003 Hradec Kralove, Czech Republic Email kamil.kuca@fnhk.cz (c) (1) (5) 2016 Bǔgga et al. This work is published and licensed by Dove Medical Press Limited. The full terms of this license are available at https://www.dovepress.com/terms.php hereby accept the Terms. Non-commercial uses of the work are permitted without any further (ermission from Dove Medical Press Limited, provided the work is properly attributed. For permission for commercial use of this work, please see paragraphs 4.2 and 5 of our Terms (https://www.dovepress.com/terms.php). 
risk of obesity-related comorbidities. ${ }^{4}$ The current standard therapy for type 2 diabetes mellitus (T2DM) is pharmacotherapy. Several randomized controlled trials (RCTs) performed in obese patients showed remission of T2DM after bariatric surgery. Recent RCTs have shown bariatric procedures to produce a similar effect in nonmorbidly and nonseverely obese insulin-dependent T2DM patients, suggesting the procedures currently used in bariatric surgery as new therapeutic approaches in patients with T2DM. ${ }^{5}$ Obesity is considered a risk factor for the development of T2DM. ${ }^{6}$ For patients with class 2 obesity (BMI $>35 \mathrm{~kg} / \mathrm{m}^{2}$ ) with comorbidities and patients with class 3 obesity (BMI $>40$ $\mathrm{kg} / \mathrm{m}^{2}$ ), bariatric surgery is recommended when conservative attempts do not result in substantial weight loss. Existing evidence, such as that of the DiaSurg study suggest that bariatric surgery not only leads to substantial weight loss but also to T2DM remission in $42 \%-78 \%$ of patients who have undergone bariatric surgery. ${ }^{7,8}$

The aim of this study is to evaluate the therapeutic efficacy of three bariatric surgery procedures, the laparoscopic greater curve plication (LGCP), LSG, and RYGB methods, in obese patients with T2DM. The following variables were assessed 12 months after surgery and compared to those values preoperatively: changes in blood pressure; the effect of bariatric therapy on pharmaceutical therapy; and the effect of bariatric therapy on T2DM.

\section{Methods}

This study evaluated outcomes in 74 patients with T2DM who underwent LGCP, LSG, or RYGB in 2011 and 2012 at the Obesitology Outpatient Unit and Department of Surgery at the Vítkovice Hospital in Ostrava, Czech Republic. Patient selection for the surgical treatment of obesity followed guidelines of the International Federation for the Surgery of Obesity, ie, BMI $\geq 40 \mathrm{~kg} / \mathrm{m}^{2}, \mathrm{BMI} \geq 35 \mathrm{~kg} / \mathrm{m}^{2}$ with associated comorbidities, or BMI $<35 \mathrm{~kg} / \mathrm{m}^{2}$ and a medical history of weight loss after intensive obesity treatment, followed by weight regain. ${ }^{3}$ For each of the procedures, the following hypotheses were tested:

- Hypothesis 1: Blood pressure will decrease 12 months after surgery, without a significant difference among individual procedure groups. The dose of antihypertensive medication will be reduced, commensurate with the decrease in blood pressure.

- Hypothesis 2: T2DM will improve 12 months after surgery, with commensurate dose reduction of oral hypoglycemic agents and insulin.

The hypotheses were tested with the Bonferroni method. ${ }^{9}$ This method compares the means of all possible pairs, ie, it compares $I(I-1) / 2$ pairs. Two median values $\mu_{\mathrm{i}}$ and $\mu_{\mathrm{j}}$ then differ at the significance level $\alpha$, if it holds true that:

$$
\left|M_{i}-M_{j}\right| \geq t_{\frac{\alpha}{m}}(N-I) \sqrt{\frac{S_{E}}{N-I} \cdot\left(\frac{1}{n_{i}}+\frac{1}{n_{j}}\right)},
$$

where $t_{\alpha / m}(N-I)$ is the Student distribution quantil and $m$ represents the number of all possible comparisons, $m=I(I-1) / 2$.

Normality of data distribution was assessed on the basis of skewness and kurtosis. Data with normal distribution were tested with the paired $t$-test, while data without normal distribution were tested with the paired Wilcoxon test. The statistical tests were evaluated at a $5 \%$ level of significance.

The research set included 74 patients, 23 men and 51 women. Patient age ranged from 33 to 70 years, with a mean of $52.7 \pm 9.12$ months. The mean age of the men was 54.2 years and that of the women was 52.0 years. The most populous group was the 51-60-year bracket, which reflects the fact that people of this age are often obese. Moreover, most patients who undergo bariatric procedures have obesity of a higher class. There were no patients under 30 years of age in the study, which corresponds with the fact that occurrence of T2DM in the population increases with age. Approximately $39 \%$ of the patients underwent LGCP, 38\% underwent RYGB, and $23 \%$ underwent LSG. The study was approved by the ethical committee at the Faculty of Medicine, University of Ostrava, in accordance with the ethical standards of the Helsinki Declaration of 1975, as revised in 2000. All subjects were carefully instructed both verbally and in writing about the aims of the study and provided written, informed consent.

\section{Results}

The impact of bariatric surgery on T2DM, changes in hypertension, and changes in pharmaceutical therapy are described.

\section{Changes in hypertension}

Blood pressure was recorded before surgery for all patients; however, values 12 months after surgery were recorded for less than half of them. Average systolic blood pressure before surgery for the entire set was $141 \mathrm{mmHg}(\sigma=16.21)$. By 12 months after surgery, blood pressure had decreased by $16 \mathrm{mmHg}$, on average $(\sigma=8.99)$. One year after LGCP and RYGB surgery, the average systolic blood pressure was $127.9 \mathrm{mmHg}(\sigma=6.99-8.99)$. LGS patients had an average blood pressure of $117.5 \mathrm{mmHg} 12$ months after surgery $(\sigma=8.86)$. According to the Czech Diabetes Society (CDS), ${ }^{10}$ a decrease in blood pressure to below $130 / 80 \mathrm{mmHg}$ is 


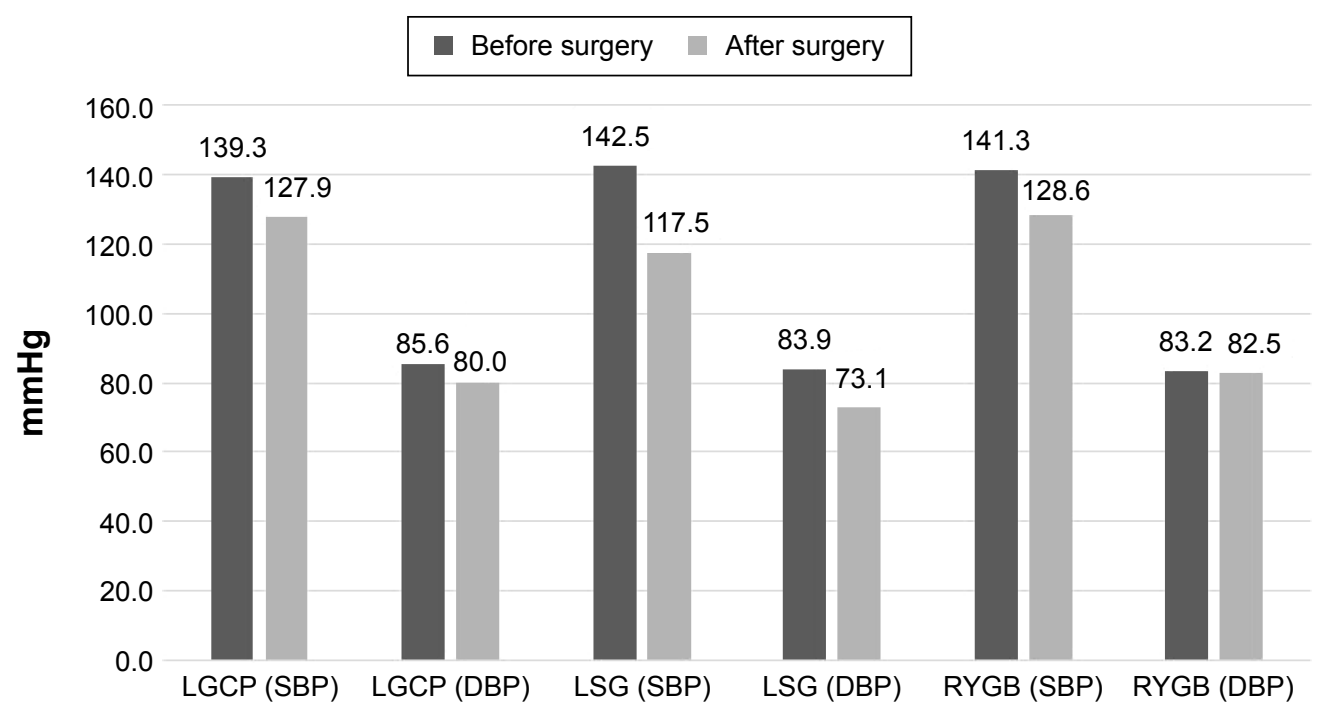

Figure I Comparison of average blood pressure values before, and 12 months after surgery.

Abbreviations: LGCP, laparoscopic greater curve plication; LSG, laparoscopic sleeve gastrectomy; RYGB, Roux-en-Y gastric bypass; SBP, systolic blood pressure; DBP, diastolic blood pressure.

considered a success in the treatment of hypertensive diabetic patients. Average systolic blood pressure values 12 months after surgery were below $130 \mathrm{mmHg}$ for all procedure groups. Diastolic pressure was $80 \mathrm{mmHg}$ on average (Figure 1).

Blood pressure in 11 of 17 patients (65\%) was below $130 / 80$, and was below 140/90 in an additional five patients (29\%). Bonferroni comparisons revealed no statistically significant differences among individual procedure types in blood pressure reduction after surgery.

\section{Changes in pharmaceutical therapy}

The last area we investigated was the effect of bariatric surgery on pharmaceutical therapy of patients. The research set included 74 patients, both men and women. Fifty patients had been taking medication for high blood pressure, and data about the course of their treatment was recorded 12 months after surgery for 44 patients. Within the entire set, medication was reduced in $68 \%$ of cases, and $25 \%$ of patients discontinued medication altogether. Grouped by surgery type, LGCP resulted in medication reduction in 53\% of patients, of whom $20 \%$ discontinued medication altogether. After LSG, medication was reduced in $70 \%$ of patients, of whom $30 \%$ discontinued medication altogether. As for RYGB, 79\% of patients had reduced medication 12 months after surgery, and $26 \%$ of these had discontinued medication altogether (Table 1).

Table I Overview of changes in antihypertensive pharmacotherapy 12 months after the surgery

\begin{tabular}{|c|c|c|c|c|c|}
\hline \multirow[t]{2}{*}{ Type of surgery } & \multicolumn{5}{|c|}{ Changes in antihypertensive pharmacotherapy } \\
\hline & $\mathbf{0} \%$ & $\leq 49 \%$ & $50 \%-99 \%$ & $100 \%$ & Total \\
\hline \multicolumn{6}{|l|}{ LGCP } \\
\hline $\mathrm{n}$ & 7 & 2 & 3 & 3 & 15 \\
\hline$\%$ & 46.7 & 13.3 & 20.0 & 20.0 & 100.0 \\
\hline \multicolumn{6}{|l|}{ LSG } \\
\hline $\mathrm{n}$ & 3 & 1 & 3 & 3 & 10 \\
\hline$\%$ & 30.0 & 10.0 & 30.0 & 30.0 & 100.0 \\
\hline \multicolumn{6}{|l|}{ RYGB } \\
\hline $\mathrm{n}$ & 4 & I & 9 & 5 & 19 \\
\hline$\%$ & 21.1 & 5.3 & 47.4 & 26.3 & 100.0 \\
\hline \multicolumn{6}{|l|}{ Total } \\
\hline $\mathrm{n}$ & 14 & 4 & 15 & II & 44 \\
\hline$\%$ & 31.8 & 9.1 & 34.1 & 25.0 & 100.0 \\
\hline
\end{tabular}

Notes: Overall, there was a statistically significant difference in the doses of drugs before and after treatment $(P<0.00 \mathrm{I})$. When evaluating various types of operations, the difference in doses of drugs before and after treatment was not significant in LSG ( $P=0.072)$, a statistically significant difference was found in other types of operations (LGCP, $P=0.046 ; R Y G B, P=0.002$ ). In case of types of surgery detected a statistically significant difference (LGCP, $P=0.046 ; R Y G B, P=0.002$ ).

Abbreviations: LGCP, laparoscopic greater curve plication; LSG, laparoscopic sleeve gastrectomy; RYGB, Roux-en-Y gastric bypass. 
Table 2 Overview of changes taking oral antidiabetic drugs 12 months after surgery

\begin{tabular}{|c|c|c|c|c|c|}
\hline \multirow[t]{2}{*}{ Type of surgery } & \multicolumn{5}{|c|}{ Change in oral antidiabetic 12 months after surgery } \\
\hline & $0 \%$ & $\leq 49 \%$ & $50 \%-99 \%$ & $100 \%$ & Total \\
\hline \multicolumn{6}{|l|}{ LGCP } \\
\hline $\mathrm{n}$ & 2 & 0 & 9 & 10 & 21 \\
\hline$\%$ & 9.5 & 0.0 & 42.9 & 47.6 & 100.0 \\
\hline \multicolumn{6}{|l|}{ LSG } \\
\hline $\mathrm{n}$ & 2 & 0 & 6 & 3 & II \\
\hline$\%$ & 18.2 & 0.0 & 54.5 & 27.3 & 100.0 \\
\hline \multicolumn{6}{|l|}{ RYGB } \\
\hline $\mathrm{n}$ & 6 & 0 & 9 & 9 & 24 \\
\hline$\%$ & 25.0 & 0.0 & 37.5 & 37.5 & 100.0 \\
\hline \multicolumn{6}{|l|}{ Total } \\
\hline $\mathrm{n}$ & 10 & 0 & 24 & 22 & 56 \\
\hline$\%$ & 17.9 & 0.0 & 42.9 & 39.3 & 100.0 \\
\hline
\end{tabular}

Notes: The results of statistical calculations show statistically significant differences in all surgery types of $P<0.001, P<0.01$ I, and $P<0.00$ I for LGCP, LSG, and RYGB, respectively.

Abbreviations: LGCP, laparoscopic greater curve plication; LSG, laparoscopic sleeve gastrectomy; RYGB, Roux-en-Y gastric bypass.

Of the 74 total patients, 64 used oral hypoglycemic agents and 23 used insulin. Data on the use of oral hypoglycemic agents 12 months after surgery were recorded for 56 patients. Within this set, $82 \%$ had reduced medication, and 39\% had discontinued medication altogether. The CDS (2012) ${ }^{10}$ considers a $50 \%$ reduction in the use of oral hypoglycemic agents a therapeutic success. This reduction was achieved by $90 \%, 81 \%$, and $82 \%$ of LGCP, LSG, and RYGB patients, respectively (Table 2).

Twenty-three patients in the research set used insulin. All of these patients experienced improvement 12 months after surgery, and more than half of them had discontinued insulin altogether. A $25 \%$ reduction in the use of insulin, considered a therapeutic success by the CDS (2012), was achieved in all patients, regardless of procedure. The RYGB group contained the largest proportion of patients using both insulin and oral hypoglycemic agents (Table 3 ).

RYGB yielded a less prominent reduction in oral hypoglycemic agents compared to the other procedures. It should be noted, however, that discontinuation of insulin alone should be considered a success.

\section{Impact of bariatric surgery on T2DM}

This section summarizes the results of previous measurements independent of type of surgery. Patients selected for the research were diabetics treated with diet, oral antidiabetics (OADs), or insulin. The outcome of the treatment was seen in only 57 patients 12 months after surgery. Twenty-three patients were treated with a combination of insulin and OADs, and 34 received only OADs. A complete withdrawal of drugs

Table 3 Overview of changes in the insulin therapy 12 months after the surgery

\begin{tabular}{|c|c|c|c|c|c|}
\hline \multirow[t]{2}{*}{ Type of surgery } & \multicolumn{5}{|c|}{ Change in insulin 12 months after surgery } \\
\hline & $0 \%$ & $\leq 49 \%$ & $50 \%-99 \%$ & $100 \%$ & Total \\
\hline \multicolumn{6}{|l|}{ LGCP } \\
\hline $\mathrm{n}$ & 0 & 1 & 1 & 2 & 4 \\
\hline$\%$ & 0.0 & 25.0 & 25.0 & 50.0 & 100.0 \\
\hline \multicolumn{6}{|l|}{ LSG } \\
\hline $\mathrm{n}$ & 0 & 0 & 2 & 2 & 4 \\
\hline$\%$ & 0.0 & 0.0 & 50.0 & 50.0 & 100.0 \\
\hline \multicolumn{6}{|l|}{ RYGB } \\
\hline $\mathrm{n}$ & 0 & 0 & 7 & 8 & 15 \\
\hline$\%$ & 0.0 & 0.0 & 46.7 & 53.3 & 100.0 \\
\hline \multicolumn{6}{|l|}{ Total } \\
\hline $\mathrm{n}$ & 0 & 1 & 10 & 12 & 23 \\
\hline$\%$ & 0.0 & 4.3 & 43.5 & 52.2 & 100.0 \\
\hline Symmetry test, $P<0.001$ & & & & & \\
\hline
\end{tabular}

Abbreviations: LGCP, laparoscopic greater curve plication; LSG, laparoscopic sleeve gastrectomy; RYGB, Roux-en-Y gastric bypass. 
was registered in 19 patients (33.3\%), four patients completely stopped taking insulin and OADs. Fifteen patients taking OADs before surgery stopped taking these drugs 12 months from the surgery. Only one diabetic who was taking OADs had no changes in health. About $82 \%$ of the entire sample showed changes in OADs to $\leq 50 \%$ of the original dose before the surgery. About $60 \%$ of patients showed changes in insulin dose to $\leq 25 \%$ of the OADs and insulin.

Serum glucose concentration was evaluated in 60 patients before and 12 months after surgery. Physiological glucose values $(<6 \mathrm{mmol} / \mathrm{L})$ were reached by 40 patients, ie, $67 \%$ of this group, 12 months after surgery. The value of $\mathrm{HbAlc}$ 12 months after the surgery was analyzed in 46 patients, values $<4.8 \%$ were achieved by 38 patients ( $83 \%$ ). Approximately $77 \%$ (24 patients out of 31 ) of the patients achieved blood glucose values $\leq 6 \mathrm{mmol} / \mathrm{L}$ and $\mathrm{HbAlc}<4.8 \%$. The HbA1c values, 12 months after the surgery were $<4.8 \%$, thus leading to withdrawal of the OADs and insulin in $80 \%$ of patients ( 8 out of 10). Nine patients from the complete set of ten $(90 \%)$ achieved remission of diabetes.

\section{Summary}

In evaluating the study hypotheses, we can say that Hypothesis 1 and 2 showed differences among individual bariatric procedures.

\section{Hypothesis I}

Blood pressure will decrease 12 months after surgery, without a significant difference among individual procedure groups. The dose of antihypertensive drugs will be reduced commensurate with the decrease in blood pressure.

This hypothesis cannot be rejected. One year after surgery, both systolic and diastolic blood pressure values had decreased, without a statistically significant difference among individual procedure types. For all procedures, blood pressure values remained below 130/80 mmHg 12 months after surgery. Within the entire set, $68 \%$ of cases had reduced their medication, and $25 \%$ had discontinued medication altogether.

\section{Hypothesis 2}

T2DM will improve 12 months after surgery, with a commensurate dose reduction of oral hypoglycemic agents and insulin.

One year after surgery, $33 \%$ of patients had discontinued oral hypoglycemic agents and insulin altogether. Approximately $79 \%$ of patients experienced improvement. Eighty-three percent of patients had attained the target value of $\mathrm{HbA}_{1 \mathrm{c}}(<4.8 \%)$. If discontinuation of insulin and oral hypoglycemic agents concurrent with $\mathrm{HbA}_{1 \mathrm{c}}$ levels below $4.8 \%$ are the criteria for diabetes remission, then T2DM remission was achieved in eight of ten patients for whom data were available. Average $\mathrm{HbA}_{1 \mathrm{c}}$ values decreased below $4.5 \%(\sigma=0.76)$. T2DM improved. Thus, the hypothesis was not rejected.

\section{Discussion}

In addition to T2DM and dyslipidemia, many of the patients in this study had hypertension. The average systolic blood pressure values 12 months after surgery did not represent a critical cardiovascular system load, ie, they had decreased below the $130 \mathrm{mmHg}$ criterion proposed by the CDS (2012). There was no statistically significant difference in mean systolic blood pressure change among the individual procedure types. One year after surgery, $65 \%$ of the set had attained optimal values $(<130 / 80 \mathrm{mmHg})$, and an additional $29 \%$ of the set had attained improvement of hypertension $(<140 / 90 \mathrm{mmHg})$. These values correlate with the findings of a meta-analysis by Buchwald et al, ${ }^{11}$ who authors reported that optimum blood pressure values were attained by $62 \%$ of patients after bariatric surgery and that an additional $17 \%$ improved. Sugerman et $\mathrm{al}^{12}$ researched the effect of gastric bypass on hypertension. The authors reported that blood pressure had returned to normal in $69 \%$ of patients 12 months after surgery. DePaula et $\mathrm{a}^{13}$ researched the relationship between sleeve gastrectomy and hypertension. Their study found that $88 \%$ of patients attained normal blood pressure. Based on the abovementioned studies, there exists a correlation, albeit slight, between blood pressure values after surgery and the type of procedure performed. The fact that no significant differences were found between individual procedure groups in this study may result from the small number of patients whose blood pressure was recorded after bariatric surgery.

One year after surgery, $33 \%$ of patients had discontinued oral hypoglycemic agents and insulin altogether. Improvement, ie, decrease of oral hypoglycemic agents by at least $50 \%$ and decrease of insulin dose by at least 25\% (according to the recommendations given by the $\left.\mathrm{CDS}^{14}\right)$, was reported in $79 \%$ of patients. Normal $\mathrm{HbA}_{1 \mathrm{c}}$ levels $(<4.8 \%)$ were attained by $83 \%$ of patients. These results are similar to those of the meta-analysis by Buchwald et al. ${ }^{11}$ If discontinuation of insulin and oral hypoglycemic agents concurrent with reducing $\mathrm{HbA}_{1 \mathrm{c}}$ below $4.8 \%$ are considered as the criteria for diabetes remission, then T2DM remission was achieved in eight out of ten patients for whom data were available. However, if remission is defined as $\mathrm{HbA}_{1 \mathrm{c}}$ decrease below $4.8 \%$ without 
discontinuation of medication, as proposed by Svačina, ${ }^{15}$ then T2DM remission was achieved by $83 \%$ of patients in this study. Svačina ${ }^{15}$ reported that $50 \%$ of gastric bypass and sleeve gastrectomy patients achieved T2DM remission. The other half of the patients experienced improvement in diabetes symptoms. All patients discontinued insulin. The majority, however, including patients with remission, continued metformin therapy. The decision not to discontinue oral hypoglycemic agents may be made because patients for whom surgical therapy is indicated often have diabetes with poorer compensation and of longer duration. ${ }^{15}$

The lack of data on the exact duration of diabetes is a disadvantage in this study, because the longer diabetes lasts, the lower the probability of remission. ${ }^{15}$ Adjustments in pharmaceutical therapy after surgery also depend on the willingness of the patient to address the issue with the attending physician. The difference between our results and those of Svačina ${ }^{15}$ could have been caused by this factor. A further challenge lies in the lack of consensus in the literature concerning the definition of T2DM. ${ }^{16}$

This study did not find statistically significant differences among individual procedure types regarding the effect on T2DM. However, previous studies have found differences among the procedures. Schauer et $\mathrm{al}^{17}$ described one such difference between LSG and RYGB. The target $\mathrm{HbA}_{1 \mathrm{c}}$ value $(\leq 6 \%)$ was attained by $37 \%$ patients after LSG and by $42 \%$ after RYGB. Although the authors stated that there was no significant difference between the patient groups for the two bariatric procedures, an important fact is that the RYGB patients attained this value without any medication, whereas $28 \%$ of the LSG patients used at least one oral hypoglycemic agent. And it was precisely the need for oral hypoglycemic agents that decreased significantly after both surgery types. There was a $4 \%$ decrease in the need for insulin in the RYGB group and an $8 \%$ decrease in the LSG group. From this viewpoint, gastric bypass was more effective for diabetes remission.

Boza et $\mathrm{al}^{18}$ studied the effect of gastric bypass on T2DM. They reported that $53 \%$ of patients achieved full remission, an additional $10 \%$ achieved partial remission, and $26 \%$ had an improvement in T2DM. Glycemia changes after LSG were described also by Vidal et al. ${ }^{19}$ More than $75 \%$ of patients in that study experienced improvement of T2DM within 3 years of the procedure.

Surgical treatment of T2DM is a subject that has been discussed in depth in recent literature. ${ }^{20}$ Changes in the parameters of glucose metabolism in this study were not so surprising. Recently, many studies have shown a positive effect of LSG on the metabolism of glucose. Peterli et $\mathrm{al}^{21}$ have proved that, 1 week following LSG, significant hormonal changes occur, which are accompanied by increased insulin, GLP-1, and PYY levels. Those changes, as well as decreased Ghrelin levels can be a guide to explain the changes after LSG. ${ }^{22}$ However, the precise mechanisms responsible for these changes have not yet been completely understood. One of the explanations for the LSG effect on glucose mechanism is its influence on the production of insulinotropic GLP-1 hormone, secreted mainly by $\mathrm{L}$ and $\mathrm{K}$ intestinal cells in response to the presence of nutrients in the intestine lumina. Metabolic interventions (mainly malabsorption) dramatically increase the secretion of certain hormones, usually in the proximal parts of intestines, also intervening with the enteroinsular axis. ${ }^{23}$ However, a mere impact of incretins is perhaps not the only mechanism of metabolic intervention effect. Vagal nerve stimulation is also highly accountable, as well as alterations of vagal signals, followed by the effects of gastric evacuation capability.

The effect of LGCP on T2DM in this study was described; $18 \%$ of these patients achieved remission and $55 \%$ experienced improvement (weight loss summary results). In view of the presented findings, and considering the various factors that influence the results, it is very difficult to make a definitive statement about the efficacy of individual bariatric procedure types in the treatment of T2DM.

\section{Acknowledgment}

This study was supported by a grant from the Ministry of Education of the Czech Republic, allocated via the University of Ostrava under registration number SGS20/LF/2014 and projects FNHK and FIM.

\section{Disclosure}

The authors report no conflicts of interest in this work.

\section{References}

1. Dobbs R, Sawers C, Thompson F, et al. How the world could better fight obesity [Internet]. Report of the McKinsey Global Institute. Available from: http:/www.mckinsey.com/insights/economic_studies/ how_the_world_could_better_fight_obesity. Accessed June 6, 2015.

2. Maglione MA, Gibbons MM, Livhits M, et al. Bariatric Surgery And Nonsurgical Therapy in Adults with Metabolic Conditions And A Body Mass Index of 30.0 to $34.9 \mathrm{Kg} / \mathrm{m}^{2}$. Comparative Effectiveness Review 82 [AHRQ Publication No. 12(13)-EHC139-EF]. Rockville, MD: Agency for Healthcare Research and Quality; 2013. Available from: http:// www.effectivehealthcare.ahrq.gov/ehc/products/227/1482/weight-losssurgery-report-130529.pdf. Accessed June 20, 2015

3. Fried M, Hainer V, Basdevant A, et al. Interdisciplinary European guidelines on surgery of severe obesity. Obes Facts. 2008;1:52-59.

4. Kenngott HG, Clemens G, Gondan M, et al. DiaSurg 2 trial - surgical vs. medical treatment of insulin-dependent type 2 diabetes mellitus in patients with a body mass index between 26 and $35 \mathrm{~kg} / \mathrm{m}^{2}$ : study protocol of a randomized controlled multicenter trial - DRKS00004550. Trials. $2013 ; 14: 183$. 
5. Meisinger C, Döring A, Thorand B, Heier M, Löwel H. Body fat distribution and risk of type 2 diabetes in the general population: are there differences between men and women? The MONICA/KORA Augsburg cohort study. Am J Clin Nutr. 2006;84(3):483-489.

6. Fried M, Yumuk V, Oppert JM, et al. Interdisciplinary European guidelines on metabolic and bariatric surgery. Obes Surg. 2014;24(1):42-55

7. Fischer L, Wekerle AL, Bruckner T, et al. BariSurg trial: sleeve gastrectomy versus Roux-en-Y gastric bypass in obese patients with BMI 35-60 kg/m $\mathrm{m}^{2}-$ A multi-centre randomized patient and observer blind non-inferiority trial. BMC Surg. 2015;15:87.

8. Fischer L, Hildebrandt C, Bruckner T, et al. Excessive weight loss after sleeve gastrectomy: a systematic review. Obes Surg. 2012;22(5): 721-731.

9. Anděl J. Fundamentals of Mathematical Statistics. Prague, Czech Republic: Matfy-Zpress; 2005.

10. The Czech Diabetes Society (CDS). Homepage of The Czech Diabetes Society. Available from: http://www.diab.cz/. Accessed June 6, 2015.

11. Buchwald H, Avidor Y, Braunwald E, et al. Bariatric surgery: a systematic review and meta-analysis. JAMA. 2004;292(14):1724-1737.

12. Sugerman HJ, Starkey JV, Birkenhauer R. A randomized prospective trial of gastric bypass versus vertical banded gastroplasty for morbid obesity and their effects on sweets versus non-sweets eaters. Ann Surg. 1987;205(6):613-624.

13. DePaula AL, Stival AR, Halpern A, Vencio S. Surgical treatment of morbid obesity: mid-term outcomes of the laparoscopic ileal interposition associated to a sleeve gastrectomy in 120 patients. Obes Surg. 2011;21(5):668-675.

14. Czech Diabetes Society. Doporučeny postup peče o diabetes mellitus 2 . Typu. [Recommended process of care for type 2 diabetes mellitus]. Available from: http:/www.diab.cz/dokumenty/dm2_12.pdf. Accessed June 20, 2015. Czech.
15. Svačina S̆. Diabetes, bariatric surgery: a practical guide to the pros and cons. Postgrad Med. 2012;14:39-41.

16. Matoulek M, Svačina S S, Lajka J. Výskyt obezity a jejích komplikací v České republice [The incidence of obesity and its complications in the Czech Republic]. Vnitřni lékařství. 2010;56(10):1019-1027. Czech.

17. Schauer PR, Kashyap SR, Wolski K, et al. Bariatric surgery versus intensive medical therapy in obese patients with diabetes. $N$ Engl J Med. 2012;366(17):1567-1576

18. Boza C, Valderas P, Daroch DA, et al. Metabolic surgery: Roux-en-Y gastric bypass and variables associated with diabetes remission in patients with BMI <35. Obes Surg. 2014;24(8):1391-1397.

19. Vidal JA, Ibarzabal F, Romero S, et al. Type 2 diabetes mellitus and the metabolic syndrome following sleeve gastrectomy in severely obese subjects. Obes Surg. 2008;18(9):1077-1082.

20. Zimmet P, Alberti KG. Surgery or medical therapy for obese patients with type 2 diabetes? N Engl J Med. 2012;366(17):1635-1636.

21. Peterli R, Wölnerhanssen B, Peters $T$, et al. Improvement in glucose metabolism after bariatric surgery comparison of laparoscopic Rouxen-Y gastric bypass and laparoscopic sleeve gastrectomy a prospective randomized trial. Ann Surg. 2009;250(2):234-241.

22. Mingrone G, Castagneto-Gissey L. Mechanisms of early improvement resolution of type 2 diabetes after bariatric surgery. Diabetes Metab 2009;35(6 Pt 2):518-523.

23. Fried M, Ribaric G, Buchwald JN, Svacina S, Dolezalova K, Scopinaro N. Metabolic surgery for the treatment of type 2 diabetes in patients with BMI $35 \mathrm{~kg} / \mathrm{m}^{2}$ : an integrative review of early studies. Obes Surg. 2010; 20(6):776-790.
Therapeutics and Clinical Risk Management

\section{Publish your work in this journal}

Therapeutics and Clinical Risk Management is an international, peerreviewed journal of clinical therapeutics and risk management, focusing on concise rapid reporting of clinical studies in all therapeutic areas, outcomes, safety, and programs for the effective, safe, and sustained use of medicines. This journal is indexed on PubMed Central, CAS,

\section{Dovepress}

EMBase, Scopus and the Elsevier Bibliographic databases. The manuscript management system is completely online and includes a very quick and fair peer-review system, which is all easy to use. Visit http://www.dovepress.com/testimonials.php to read real quotes from published authors. 